\title{
Küre Dağları ve Ilgaz Dağı Milli Parklarında Ziyaretçi Yönetim Araçlarının Değerlendirilmesi
}

\author{
Gamze ÇOBAN ${ }^{*}$, Tendü Hilal GÖKTUĞ ${ }^{2}$ \\ ${ }^{1}$ Düzce Üniversitesi, Orman Fakültesi, Peyzaj Mimarlı̆̆ı Bölümü, DÜZCE \\ ${ }^{2}$ Aydın Adnan Menderes Üniversitesi, Ziraat Fakültesi, Peyzaj Mimarlı̆̆ı Bölümü, AYDIN
}

\section{Öz}

Zengin doğal ve kültürel kaynaklara sahip olan korunan alanlar, insanlar için kentin yoğunluğundan uzaklaşarak kendini yenilemeyi sağlayan önemli doğal alanlardır. Korunan alanlar içerisinde yer alan milli parklar, doğal ekosistemin oluşturduğu zengin peyzaj özelliklerini barındırmasının yanı sıra rekreasyonel ve turizm açıdan da yüksek potansiyele sahiptir. Ulusal ve uluslararası ölçekte öneme sahip milli parkların sürdürülebilir kullanımı uluslararası düzeyde önem gösterilen bir konu haline gelmiştir. Kaynak değerleri bakımından zengin olan korunana alanların sürdürülebilir kullanımına yönelik ziyaretçi yönetim araçları geliştirilmiştir. Ziyaretçi yönetim araçları, alanda oluşabilecek olumsuzluklara karşı önlem alınması yönünde geliştirilen sinırlandırmalar, etkinlikler veya çözümlerdir. Ülkemizde de bu tür uygulamalar yavaş yavaş kullanılmaya başlanmaktadır.

Bu çalışmada Kastamonu ili sınırları içerinde yer alan kaynak değerleri bakımından zengin, Küre Dağı ve Ilgaz Dağı milli parkları çalışma alanı olarak seçilmiştir. Bu alanların sahip olduğu yönetim planları, rekreasyonel faaliyetlerin durumu, yönetim açısından karşılaşılan sorunlar ve belirlenen ziyaretçi yönetim araçlarının kullanıma yönelik konulara odaklanılarak oluşturulan anket formu, 2015 yılı Mayıs ayında 10. Orman Bölge Müdürlüğüne gönderilerek belirtilen konularda veriler elde edilmiş̧ir. Verilerin değerlendirilmesiyle iki alanın durumu karşılaştırılarak, ziyaretçi yönetim araçları temelinde sürdürülebilir kullanımları açısından bazı öneriler getirilmiştir.

Anahtar Kelimeler: Korunan Alan, Milli Park, Küre Dağı Milli Parkı, Ilgaz Dağı Milli Parkı, Ziyaretçi Yönetim Araçları.

\section{Evaluation of Visitor Management Tools In Küre Mountains and Ilgaz Mountain National Park}

\begin{abstract}
Protected areas, which have rich natural and cultural resources, are important natural areas that enable people to move away from the density of the city and renew themselves. The national parks within the protected areas have a rich potential for recreation and tourism as well as the rich landscaping features of the natural ecosystem. Sustainable use of national parks of national and international importance has become an internationally important issue. Visitor management tools have been developed for the sustainable use of protected areas which are rich in resource values. Visitor management tools are limitations, activities or solutions that are developed to take measures against possible negative impacts in the field. In our country, such applications are gradually being used.

In this study, Küre Mountain and Ilgaz Mountain national parks, which are rich in terms of source values within the boundaries of Kastamonu province, were selected as the study area. that management plans have of these areas, the status of recreational activities, problems encountered in terms of management and focusing on issues concerning the use of designated visitor management tool created questionnaire, in May 2015. 10. The data in the matters referred sent to the Regional Directorate of Forestry was obtained. By evaluating the data, the situation of the two areas was compared and some suggestions were made in terms of sustainable use on the basis of visitor management tools.
\end{abstract}

Keywords: Protected Area, National Park, Küre Mountain National Park, Ilgaz Mountain National Park, Visitor Management Tools 


\section{Giriş}

Günümüzde milli parklar, doğal ekosistemin oluşturduğu zengin peyzaj özellikleriyle rekreasyonel açıdan yüksek potansiyele sahip alanlardır. Akten ve Gül (2014)'e göre, sosyal, ekonomik, kültürel, teknolojik gelişmelere paralel olarak ulaşımın artmasıyla insanların rekreasyonel taleplerinde önemli değişimler meydana gelmiştir. Ayrıca kentsel alanlarda açık yeşil alanların nitelik ve nicelik açısından yetersizliği kentte yaşayan kişileri kente yakın doğal alanlara yönlendirmektedir. Kentsel alanlara yakın olan doğal alanların başında milli parklar önemli bir çekim merkezi haline gelmiş olup, rekreasyonel faaliyetler açısından kullanım imkanı sağlamaktadır. Ancak milli parklarda koruma-kullanma dengesi gözetmeksizin yapılan rekreasyon faaliyetleri, kaynak değerleri üzerinde olumsuz etkilere sebep olarak, ziyaretçi memnuniyetinde düşüşler meydana gelmiştir.

Zal (2002)'e göre, milli parkların sahip olduğu doğal, kültürel ve rekreasyonel kaynak değerlerinin korunması, geliştirilmesi ve devamlılı̆ıını sağlayacak bir etkili ziyaretçi yönetim planının hazırlanması gerekmektedir. Dolaysıyla ziyaretçi yönetim planlarının başarılı olabilmesi için alanın sürdürülebilir kullanımına yönelik stratejiler geliştirilmeli ve bu stratejilerin etkin bir şekilde uygulanabilmesi adına ziyaretçi yönetim araçlarından yararlanılmalıdır. Ziyaretçi yönetim araçları, alanda oluşabilecek olumsuzluklara karşı önlem alınması yönünde geliştirilen sınırlandırmalar, etkinlikler veya çözümler olarak tanımlanabilir (Çoban, 2016).

Mason (2005), 1991 y1linda UK Ministry of Environment the Department of Employment and the English Tourist Board (ETB) tarafindan yapılan raporda ziyaretçi yönetiminde, ziyaretçi ile çevre arasında dengenin sağlanmasında 3 önemli husustan bahsetmektedir. Bunlardan ilki ziyaretçi kapasitesinin ve dağılımının sınırlandırılması, ikincisi ziyaretçilerin kaynakla olan uyumunun sağlanması ve zararların en aza indirilmesi ve son olarak ziyaretçi davranışlarının değiştirilmesidir (Akten ve Gül, 2014). Bu konular aslında milli parklardaki sürdürülebilir kullanımına yardımcı olan ziyaretçi yönetim araçlarının belirlenmesinde temel oluşturmaktadır.

Etkin ziyaretçi yönetim araçlarının milli parklarda uygulanması, ziyaretçi memnuniyeti, hizmet kalitesi ve alanın kaynak değerlerinin korunması bağlamında oldukça önem taşımaktadır. Korunan alanların yönetiminde yaygın olarak kullanılan ziyaretçi yönetim araçların 16 başlık altında toplamak mümkündür (Manning ve Lime, 2000; Eagles ve ark., 2002; Masters ve ark., 2002, Göktuğ ve Kurkut, 2016; Çoban, 2016);

1.1.Grup Büyüklüğünün Sınırlandırılması: Grup büyüklüğ̈̈; bir turist kafilesindeki maksimum insan sayısı ile ifade edilmektedir. Grup büyüklüğünün sınırlandırılması bisiklet turları, trekking ve kamping gibi rekreasyonel aktivitelerin özellikle hassas ekosistemlerde neden olabileceği ekolojik etkilerin veya sosyal etkilerin azaltılmasına yönelik olarak kullanılan önemli ziyaretçi yönetim araçlarındandır (Eagles ve ark., 2002; Poteete ve ark., 2004).

1.2.Kullanım Düzeyinde Mevsimsel ya da Gecici Sınırlandırma: Milli park ve diğer rekreasyonel alanlarda belirli mevsimlerde, günlerde veya zaman dilimlerinde belirlenen kapasite limitlerinin üstünde yoğun taleplerle karşı karşıya kalınabilir. Böyle durumlarda, kullanım düzeyinde mevsimsel ya da geçici sınırlandırma ziyaretçi yönetiminde kullanılabilecek araçlardan biridir (Manning ve Lime, 2000). Kullanım limitleri genellikle tarihi binalar ve sit çevrelerinde, kano sporu erişimi ve doğa yürüyüş alanlarında uygulanmaktadır (Eagles ve ark., 2002).

1.3.Zonlama: Belirli rekreasyonel aktivitelerin seçilmiş alanlarda toplanması veya belirli aktivitelerin belirli alanlarda yapılmasına yönelik uygulanan ziyaretçi yönetim aracıdır. Zonlama mekânsal olabileceği gibi zamansal olarak da gerçekleştirilebilir. Ayrıca zonlama farklı rekreasyonel firsatları yaratmak için de tercih edilen alternatif yönetim araçlarından birisidir (Greist, 1975; Haas ve ark., 1987; Manning and Lime, 2000; Masters ve ark., 2002). Zonlama, bu ziyaretçi yönetim aracı, kabul edilebilir rekreasyonel kullanım etkilerinin belirlenmesinde ve buna bağlı olarak istenmeyen etkilerin yayılımının engellenmesinde yarımcı olmasının yanı sıra, herhangi bir rekreasyon konumunun içerisinde veya etrafinda yürütülen farklı rekreasyon türleri veya turizm olanaklarının daha iyi bir şekilde anlaşılmasını sağlamaktadır (Anonymous, 2002).

1.4.Ates Kullanımında Uygulanan Kısıtlamalar: Gelecek nesillere miras bırakılacak statüye sahip olan milli park ve korunan alanlarda ateş kullanımından kaçınmak bir zorunluluktur. Ateş kullanımının kısıtlanmasındaki amaç, önemli ölçüde orman yangınları potansiyelinin, alt bitki örtüsünün tahribinin, doğal alan içinde mevcut odunların yakılmasının ve bu yangın sonucunda oluşacak ekolojik etkilerin azaltılması yönündedir.

1.5.Kalıs Süresinin Sınırlandırılması: Birçok kişiye rekreasyon alanından faydalanma imkanı tanıyabilmek için kullanılan ziyaretçi yönetim araçlarından birisidir. Bu sınırlandırmalar, kamp alanlarında en fazla 3 gün kalma veya özel turlara getirilen saatlik sınırlandırmalara benzer uygulamaları içermektedir (Roggenbuck ve Schreyer, 1977; Heywood, 1985). 
1.6.Ziyaretçi Eğitim ve Bilgilendirme Uygulamaları: Yerel halk ve ziyaretçilerin doğa koruma hakkındaki bilgi eksikliği korunan alanlarda birçok problemlere yol açabilmektedir. Bu sebeple çevre eğitimi modern toplumlarda ziyaretçi yönetiminin bütünleyici bir parçası haline gelmiștir. Ekolojik bilgi ve doğa deneyimleri ile kombine edilen çevre eğitimi aktiviteleri, halkın çevre bilincini geliştirmekte ve doğal süreçlerin anlaşılmasını sağlamaktadır. Uzun vadede ise doğal ve kültürel kaynak değerlerinin korunmasını, temiz çevre ve sürdürülebilirlik anlayışının yerleşmesini sağlamaktadır (Farrell ve Marion, 2000; Manning, 2003; Marion ve Reid, 2007; Park ve ark, 2008).

1.7.Bariyer Sistemi: Milli park gibi korunan alanlarda yer alan hassas bölgelerde ziyaretçi etkilerini en aza indirmek için alana girişleri bariyer sistemleriyle engellemek mümkündür (Krug, 2001; Park ve ark, 2008). Bu sisteme ilişkin, korunan alan ve milli parklarda hassas sulak alanlar etrafina hendekler yapılarak ziyaretçileri bu alanlarda yürüyüş yapmaktan uzaklaştırmak, küçük boylu bariyerler oluşturularak araçların yeşil alanlara girmesini engellemek, hassas alanlara yakın olan yürüyüş yollarının kenarlarında eğimin artırılması gibi uygulamalar örnek verilebilir.

1.8. Rezervasyon Sistemi: Milli Parkın yoğun olarak talep edildiği belirli mevsimlerde veya günlerde ziyaretçi sayısını kontrol altında tutmak için kullanılan araçlardan biri rezervasyon sistemidir. Rezervasyonlar, mail, telefon, site kayıtları vb. yöntemlerle alınabilmektedir. Çoğunlukla çeşitli turlar vasıtası ile ziyaret edilen milli parklarda uygulanması daha kolaydır (Manning ve Lime, 2000).

1.9.Cekilis Sistemi: Yoğun taleplerin yaşandığı dönemlerde kimlerin alanı ziyaret edebileceği veya ziyaretçilerin hangi gün ve hangi saatler arasında ziyaretlerini gerçekleştirebilecekleri çekiliş yolu ile tespit edilebilir (Manning ve Lime, 2000).

1.10.Öncelikli Ziyaretçiler Sistemi: Alanı ziyaret etmek için başvuruda bulunanların daha önceden alanı ziyaret edip etmedikleri, ikamet yerlerinin Milli Parka göre uzaklık durumu, yaşları, alanda gerçekleştirilecek rekreasyonel faaliyetler için gerekiyorsa sertifikasının veya uzmanlığının olma durumu gibi kriterler göz önünde bulundurularak öncelikli ziyaretçiler veya ziyaretçi grupları belirlenebilmektedir (Manning ve Lime, 2000).

1.11.Farklı Ücretlendirme Politikaları: Ekonomide, yüksek fiyatlı malların daha az tüketileceği ve daha kaliteli hizmet sağlayacağı teorisinden yola çıkarak, ücretlendirme politikaları korunan alanlarda kullanımların sınırlandırması ve korunan alanlara maddi kaynak sağlaması yönünden etkili ve önemli yaklaşımlardan birisidir (Lindberg ve Halpenny, 2001; Buckley, 2003). Ücretlendirme politikaları, kullanımların yoğunlaştığı tatil günlerinde, kullanımın yoğun olduğu rekreasyon konumlarına yönelik, çocuklara ve yaşlılara indirim, hassas alanlara yönelik, yerli ve yabancı turist olma durumuna göre farklı durumlar dâhilinde gerçekleştirilmektedir (Manning ve Lime, 2000).

1.12.Ulașım Sistemleri: Rekreasyon alanlarında sadece ziyaretçi yoğunluğu değil aynı zamanda araç yoğunluğu özellikle motorlu araç yoğunluğu da ziyaretçi deneyim kalitesinde düşüşlere sebep olmaktadır (Manning, 1999). Bununla birlikte korunan alanlarda motorlu taşıtların vejetasyonda tahriplere, erozyona, hava ve toprak kirliliğine, bitki üzerinde ağır metal birikimine neden olduğu ve doğal yaşamı olumsuz yönde etkilediği bilinmektedir. (Anderson ve ark., 1998). Ziyaretçi ulaşımı ve sirkülasyonun başarıyla sağlanması yönünde aşağıda sıralanan eylemler gerçekleştirilmektedir (Singer ve Beattie 1986; Eaton ve Holding, 1996; Cullinane ve Cullinane, 1999) Motorlu taşıtların sınırlandırılmasıyla, anayolun sadece belirli araç türlerine kapatılması, belirli saatler arasında giriş izni verilmesi, park içerisindeki hedef bölgelerde kapasitenin sınırlandırılmasına yardımcı olmaktadır.

1.13.Reklam ve Pazarlama: Korunan doğal alanların yönetiminde rekreasyonel arz ile talebin dengelenmesi ve olumsuz etkilerin minimize edilmesi en önemli amaçlardan biridir. Dolayısıyla rekreasyonel alanların ziyaretçilere doğru şekilde tanıtılması gerekmektedir. Bu kapsamda ziyaretçilere internet siteleri aracıyla alan hakkında bilgilendirmeler yapılmakta ve belirli günlerde indirimlere gidilerek ziyaretçilerin farklı zaman aralıklarında alanı ziyaret etmesi teşvik edilmektedir (Eagles ve ark., 2002).Reklam ve pazarlama yoluyla ziyaretçilerin ilgisinin artması, alana gelir kaynağı olarak geri dönmede katkı sağlamaktadır.

1.14.Teknolojik Uygulamalar: Teknolojik uygulamalar ile ziyaretçilerin alan içerisinde güvenliği sağlanmakta ve memnuniyet seviyeleri artmaktadır. Ayrıca, ekosistemin tahrip edilmemesi yönünde de önemli yarar sağlamaktadır (Eagles ve ark., 2002). Bu uygulamalardan biri ziyaretçilerin kişisel gereksinimlerini karşılama yönünde kullanılan teknolojik uygulamalardır. Odunsu ürünlerin yakılmaması için taşınabilir ocak kullanımını zorunlu kılmak ve kişisel ihtiyaçlar için portatif tuvalet kullanımı teşvik etmek bu uygulamalara örnek olarak verilebilir. Motorlu araçların sınırlandırılması yönünde uygulanan teknolojik uygulamalara ise park sayar cihazları, servis duraklarında bekleme süresini haber veren sesli ve görsel uyarı sistemleri ile yol üzerlerinde servis duraklarının olduğu gösteren 
dijital yönlendirme levhaları örnek olarak verilebilir (Manning ve Lime, 2000; Eagles ve ark., 2002; Beunen ve ark. 2008).

1.15.Ziyaretçi Sertifikası: Sadece gerekli niteliklere sahip ziyaretçilerin girişine izin verilmesi için ziyaretçilerden tanımlı olan rekreasyon faaliyetini gerçekleştirebildiğine dair sertifika/lisans belgesi istenebilmektedir. Böylece belirli niteliklere sahip olan ziyaretçiler belirlenen kullanım süresi içinde tanımlanan rekreasyon faaliyetini gerçekleştirmektedir. Örneğin, bazı milli parklarda olta balıkçılığı, atla gezinti, dağcılık, rafting, vb. rekreasyon faaliyetlerini gerçekleştirmek için lisans belgesi/ sertifikası olan ziyaretçilere izin verilmektedir (Eagles ve ark., 2002).

1.16.Rehber Eșliğinde Tur Düzenlemek: Doğal ve kültürel değerlerce zengin olan milli park ve korunan alan sınırları içeresinde ziyaretçilere alan hakkında doğru bilgiler verip gezdiren ve gerektiğinde alandaki aktiviteler konusunda yardımcı olan kişiler alan kılavuzu ya da rehber olarak adlandırılmaktadır. Bu kişiler kaynak değerlerini koruma- kullanma ilkesi çerçevesinde belirlenen yönetim planları doğrultusunda uygulanması, alana gelen ziyaretçilerin doğru bilgilendirilmesi ve yöre insanlarının olumsuz etkileyen durumların en aza indirilmesinde rol oynamaktadırlar.

Bu çalışmada, Küre Dağı ve Ilgaz Dağı milli parklarında uygulanan ziyaretçi yönetim araçlarını incelenmiştir. Her iki milli parkın sahip olduğu kaynak değerlerin sürdürülebilir kullanımları açısından uygulanan ziyaretçi yönetim araçları karşılaştırılarak, daha etkin kullanılmasına yönelik bazı öneriler getirilmiştir.

\section{Materyal ve Yöntem}

Çalışmanın ana materyalini, 2873 sayılı Milli Parklar Kanununa göre milli park olarak ilan edilmiş Küre Dağı ve Ilgaz Dağı Milli Parkları oluşturmaktadır (Şekil 1).

Küre Dağı Milli Parkı: Kastamonu ili Pınarbaşı, Azdavay, Cide ve Şenpazar ilçeleri ile Bartın ili merkez ve Ulus ilçeleri sınırlarında arasında Küre Dağları Milli Parkı bulunmaktadır. 07.07.2000 yılında ilan milli park ilan edilmiş olup, 37. 753 hektarlık alan yüzeyine sahip milli parkın, 18.12 ha'ı Kastamonu il sınırları içerisinde bulunmaktadır (Şen ve Buğday, 2015). Küre Dağı Milli Parkının sahip olduğu kaynak değerler (Anonim, 2019a; Öztürk, 2005);

- Küre Milli parkı, Batı Karadeniz Karst Kuşağında yer almakta olup, jeolojik yapısı ve yağışın etkisiyle ortaya çıkan derin kanyonlar, boğazlar, mağaralar, şelaleler ve düden açısından Türkiye'nin ve Avrupa'nın en zengin alanlarından birisi olarak kabul edilmektedir.

- Milli park, ulusal düzeyde tehlike altında 12 bitki taksonunu içinde barındırmakta ve "Kuzey Anadolu ve Kafkasya Ilıman Kuşak Ormanları” Dünya Doğayı Koruma Vakfi'nın (WWF) doğa koruma açısından küresel düzeyde öncelikli 200 ekolojik bölgeden biri olarak nitelendirilmektedir.

- Milli parkın barındırdığı zengin biyoçeşitlilik bakımından 675 bitki türü bulunmakta olup, bunların 157 'si endemik bitki türüdür. Ayrıca içeresindeki hayvan türleri bakımından, 40 memeli ve 129 kuş türü bulunmaktadır.

- Küre dağları Milli parkı, yabanıl alanların korunması konusunda odaklanan, PAN Parks (Protected Area Network) korunan alan ağına sahip ülkemizdeki tek korunan alandır.

Ilgaz Dağı Milli Park: Batı Karadeniz Bölgesi’nin Kastamonu ili merkez ilçesi ve Çankırı ili Ilgaz ilçesi sınırlarında arasında bulunmaktadır. Milli Parkın kapladığı alan 1.118 ha olup, bu alanın 750.9 ha'ı Kastamonu ili sınırları içerisinde bulunmaktadır. 02.06.1976 yılında milli park olarak ilan edilmiştir. Karadeniz ile İç Anadolu Bölgeleri arasındaki geçiş kuşağında yer alan Ilgaz Dağları zengin tür ve habitat çeşitliliğine sahiptir (Şen ve Buğday, 2015). Ilgaz Dağı Milli Parkının kaynak değerleri şunlardır (Anonim, 2019b; Çoban, 2016);

- Arazi yapısı genellikle serpatinler, şistler ve volkanik kayaçlardan meydana gelmekte olup, dağ oluşum hareketleri, değişik karakterde vadiler, sırtlar ve doruklar yönünden ilgi çekici örnekler bulunmaktadır.

- Milli Park sınırları içinde 4'ü Ilgaz endemiği, 33'ü Türkiye'ye özgü endemik olmak üzere toplam 234 takson tespit edilmiştir. Ayrıca Milli Parkın 1055 hektarında (\%97) orman ekosistemi, 33 hektarında (\%3) çalılık ekosistemi hüküm sürmektedir. Orman ekosistemini Uludağ göknarı (Abies nordmanniana (Stev.) Spach. subsp. bornmülleriana) ile sarıçam (Pinus sylvestris) oluşturmaktadır.

- Türkiye'nin önemli kış turizm merkezlerinden biri olan Ilgaz Dağı Milli parkı, kış sporlarının yanı sıra yılın her mevsimi ziyaretçilerine rekreasyon firsatı sağlamaktadır. 


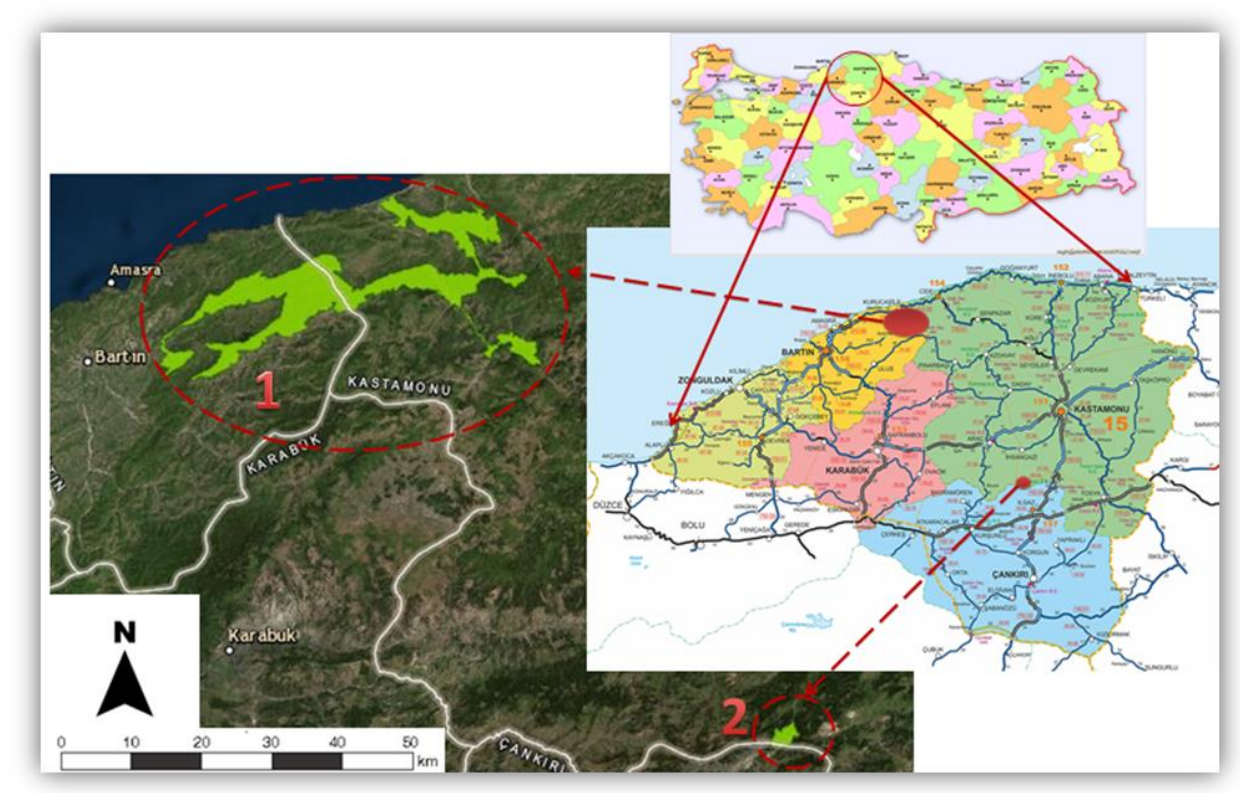

Şekil 1. Milli Parkların haritası (1: Küre Dağı Milli Parkı, 2: Ilgaz Dağları Milli Parkı)

Çalışmanın yöntemi; Şekil 2'de verilen yöntem akış şemasına göre gerçekleştirilmiştir. Bu şemaya göre ilk olarak çalışmanın amacı ortaya koyulduktan sonra, her iki milli parkın kaynak değerleri ve genel özellikleri araştırılmıştır. Daha sonra bu alanların değerlendirilebilmesine yönelik bir anket formu oluşturulmuştur. Bu anket formu milli parkların bağlı olduğu 10. Bölge müdürlüğüne 2015 Mayıs ayında gönderilip, alandan sorumlu görevliler tarafından cevaplandırılmıştır. $\mathrm{Bu}$ anket formunda alanın sürdürülebilirliğine ulaşılmasında iki temel hedef sorgulanmıştır. Bunlardan ilki her iki milli parktaki yönetim açısından karşılaşılan sorunlar diğeri ise 16 ziyaretçi yönetim aracına ilişkin toplam 52 soru hazırlanıp, milli parklarda uygulanan ziyaretçi yönetim araçları sorgulanmıştır. Elde edilen veriler doğrultusunda milli parkların kaynak değerlerini sürdürülebilir kullanımına yönelik değerlendirmeler yapılarak öneriler getirilmeye çalışılmıştır.

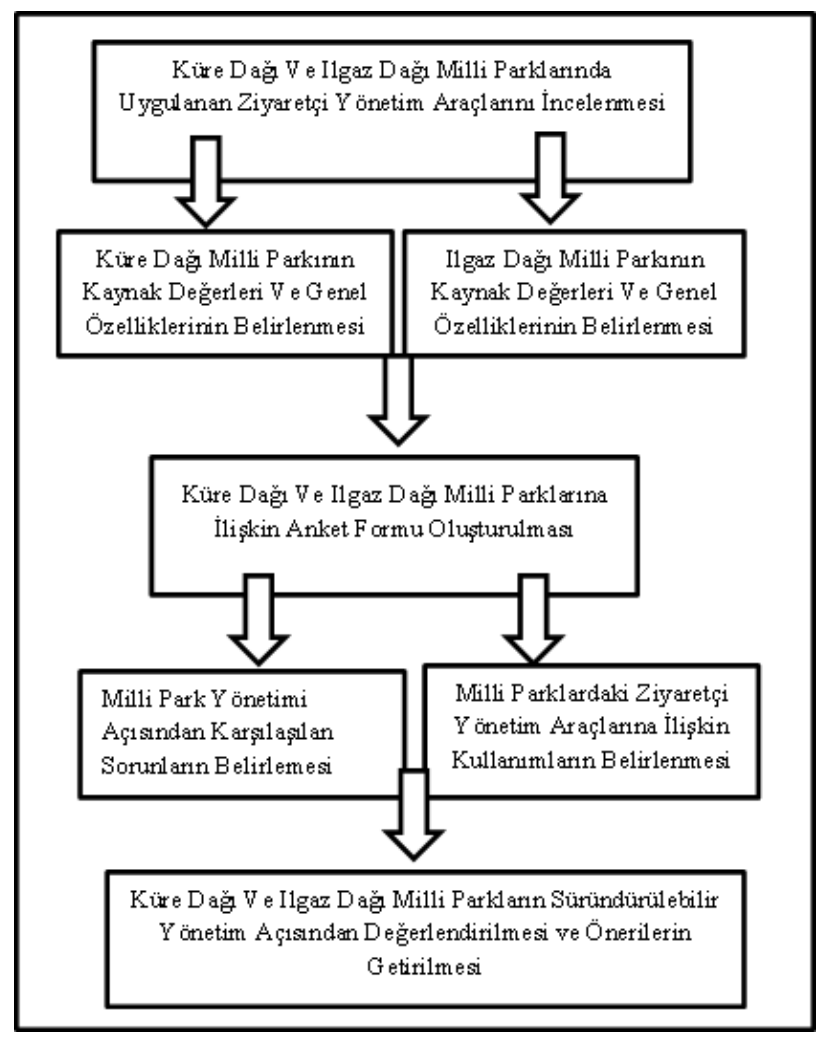

Şekil 2. Yöntem Akış Şeması 


\section{Bulgular ve Tartışma}

Alanlarla ilgili anket çalışmalarından elde edilen veriler sonra bulgular kısmını iki başlık altına ele alınmıştır. Bunlardan ilki milli parklarda yönetimsel açısından konulara ilişkin verilerin değerlendirilmesiyken, ikincisi ise milli parklarda uygulanan ziyaretçi yönetim araçlarının irdelenmesidir. Milli parklarda uygulanan ziyaretçi yönetim araçlarının irdelenmesini anlaşılır kılmak için 5 başlık altında uygulanan yönetim araçları değerlendirilmiştir. Bunlar; Giriş ücretlerine yönelik ziyaretçi yönetim araçları, Ziyaretçi ve ekosistemi korumaya yönelik ziyaretçi yönetim araçları, Ziyaretçiyi bilgilendirmeye yönelik yapılan ziyaretçi yönetim araçları, Taşıma kapasitesine yönelik geliştirilen ziyaretçi yönetim araçları, Alanın etkin kullanımına yönelik geliştirilen ziyaretçi yönetim araçlarıdır.

\subsection{Milli Parkların Yönetimsel Açısından İrdelenmesi}

Korunan alanların sürdürülebilir kullanımına yönelik oluşturulan uzun devreli gelişim planı ve ziyaretçi yönetim planlarına ilişkin ankette yer verilen gerekli alanlar her iki milli park tarafindan değerlendirilmiştir. Her iki parkta da Uzun Devreli Gelişim Planı ve Ziyaretçi Yönetim Planının olduğu belirtilmiştir.

Milli parklardaki kaynak değerlerin sürdürülebilir kullanımın sağlaması açısından yönetim planlarının hazırlanması gerekmektedir. Nitekim Ersoy ve Daşdemir (2016)'a göre, sürdürülebilir kalkınma amacıyla korunan alanlardan beklenen tüm faydaların sağlanabilmesi için etkili bir şekilde yönetilmeleri ve bunun için de iyi hazırlanmış yönetim planlarına sahip olması gerektiğini belirtmişlerdir. Küre Dağı ve Ilgaz Dağları milli parklarında yönetim planlarının olması etkin bir şekilde yönteminin sağlanması yönünde atılan en önemli adımlardan birisidir.

Ziyaretçilerin korunan alanlarda en az olumsuz etki bırakması için yönetim planlarının önemli ayağını taşıma kapasite analizleri oluşturmaktadır. Ankette taşıma kapasiteleri ile ilgili verilere bakıldığında Ilgaz Dağı Milli Parkının fiziksel, sosyal ve ekolojik taşıma kapasitelerine sahip, Küre Dağları Milli parkının bu analizleri sahip olmadığı görülmektedir.

Milli park gibi korunan alanlarda sunulan rekreasyonel olanaklar ile ziyaretçi talepleri arasında bir denge sağlanması için alanın taşıma kapasitesinin belirlenmesi gerekmektedir. Nitekim Göktuğ ve Arpa (2015), taşıma kapasitesi analizleri tabanlı ziyaretçi yönetim planlarının, doğru yönetim stratejilerinin geliştirilmesinde anahtar role sahip olduğunu belirtmektedir. Bu yüzden milli parklarda taşıma kapasite analizlerinden yararlanılmaması alanın sürdürülebilirliği açısından endişe verici bir durumdur.

Ülkemizin doğal ve kültürel kaynak değerleri yönünden zengin alanlar olan milli parklar, ziyaretçilere birçok rekreasyonel aktiviteye olanak sağlamaktadır. Milli parkların sahip olduğu rekreasyonel faaliyetler Tablo 1'de gösterilmektedir. Küre Dağı Mili parkı \% 60 oranında rekreasyonel faaliyetlere sahip iken, Ilgaz Dağı Milli Parkında ise \% 40 rekreasyonel olanaklar bulunmaktadır.

> Milli parklar kâr amacı gütmeyen kamusal alanlardan olup, tarihsel, doğal ve kültürel değerleriyle korunması gereken ve aynı zamanda açık hava rekreasyon faaliyetlerinin gerçekleştirildiği alanlardır. Dolaysıyla milli parklar sunduğu rekreasyonel faaliyetler açısından ziyaretçilere farklı deneyimler kazanmasını sağlamaktadır. Nitekim Ersoy ve Daşdemir (2016)'a göre, rekreasyonel faaliyetlerinin doğaya saygılı, koruma ve kullanma ölçülerini dengede tutabilecek şekilde planlanması gerektiğini vurgulamıştır.

Milli parkların yönetim birimlerinin karşılaştığı sorunları anlamaya yönelik ankette yer alan maddeleri 1-5 (1= Kesinlikle Hayır, 2=Hayır, 3=Orta, 4= Evet, 5=Kesinlikle Evet) arasında puanlama yapmaları istenmiştir. Yapılan puanlamaların ortalamaları alınarak Tablo 2'de veriler elde edilmiştir. Buna göre veriler değerlendirildiğinde, puanlamada 3'den büyük ortalamaların yüzdesine bakıldığında \% 64,3 olduğu görülmektedir. Bu yüzdelik oran milli parkların yönetim birimlerin yaşadığı sorunların fazla olduğu göstermektedir.

Milli parkların yönetim karşılaştığı sorunlar en başında mevcut personel sayısının az olduğu gelmektedir. Dolaysıyla milli parklar sahip olduğu kaynak değerleri koruma ve geliştirme görevini tam anlamıyla yerine getirilebilmesi için alanında uzman kişilerin çalışması gerekmektedir. Nitekim Yıldırım ve Erol (2012), ekolojik özellikler bakımından zengin olan alanların planlanmasında ve daha sonra yönetilmesinde, konusunda yetişmiş veya uzun zamanlardan beri doğa koruma konusunda çalışmış personelin istihdamına öncelik verilmesi gerektiğini belirtmişlerdir. 
Tablo 1. Milli Parklardaki Rekreasyonel Faaliyetler

\begin{tabular}{|c|c|c|}
\hline REKREASYONEL FAALIYYETLER & $\begin{array}{c}\text { Küre Dağları Milli } \\
\text { Parkı }\end{array}$ & $\begin{array}{c}\text { Ilgaz Dağı Milli } \\
\text { Parkı }\end{array}$ \\
\hline Günübirlik kullanım alanı & + & + \\
\hline Kamp alanı & + & + \\
\hline Plaj & - & - \\
\hline Yürüyüş patikaları & + & + \\
\hline Bisiklet yollart & + & - \\
\hline At ile gezinti yollart & + & - \\
\hline Tarihi veya arkeolojik alanlar & + & - \\
\hline Kuş gözlem noktaları & + & + \\
\hline Olta balıkçılı̆̆ için izin verilmiş bölgeler & + & - \\
\hline Su altı dalış noktaları & - & - \\
\hline Su sporları bölgeleri (Rafting, deniz bisikleti, kano, yelken) & - & - \\
\hline Tırmanış rotaları & - & - \\
\hline Kayak tesisi & - & + \\
\hline Yamaç paraşütü noktalarl & - & - \\
\hline Ziyaretçi tanıtım merkezi & + & + \\
\hline Yüzde Oranları & $\% 60$ & $\% 40$ \\
\hline
\end{tabular}

Tablo 2. Milli Parklarda Karşılaşılan Yönetim Sorunları

\begin{tabular}{|c|c|c|}
\hline \multicolumn{3}{|c|}{ 1= Kesinlikle Hayır, 2=Hayır, 3=Orta, $4=$ Evet, $5=$ Kesinlikle Evet } \\
\hline Milli Parklarda Karşılaşılan Yönetim Sorunları & $\begin{array}{c}\text { Küre Dağları } \\
\text { Milli Parkı }\end{array}$ & $\begin{array}{l}\text { Ilgaz Dağı } \\
\text { Milli Parkı }\end{array}$ \\
\hline Mevcut çalışan sayımız az & 5 & 5 \\
\hline Milli parkın yeterli tanıtım yapılması & 3 & 5 \\
\hline Rekreasyonel aktivite çeşitliliği az & 1 & 4 \\
\hline Ziyaretçi sayısı az & 3 & 4 \\
\hline Belirli dönemlerde ziyaretçi fazlalaşıyor & 5 & 5 \\
\hline Alanda kalabalık ve karmaşa oluşuyor & 3 & 5 \\
\hline Hafta sonları kuyruklar meydana geliyor & 1 & 3 \\
\hline Ziyaretçiler koruma-kullanma konularında bilinçsiz & 3 & 4 \\
\hline Ziyaretçiler alanı illegal olarak kullanma & 5 & 2 \\
\hline Ziyaretçilerin alanı kirletmesi & 4 & 4 \\
\hline Ziyaretçiler alanda kalıcı hasar bırakma & 4 & 2 \\
\hline Kişisel araba ile gelme sonucu sıkışıklık & 2 & 5 \\
\hline & 2 & 2 \\
\hline turlert & 2 & 2 \\
\hline
\end{tabular}

Milli park yönetim birimlerin karşılaştı̆̆ı önemli sorunlardan birisi de belirli dönemlerde alana ziyaret eden kişi sayısının fazla olduğu belirtilmiştir. Bu bağlamda ziyaretçi sayılarını sınırlandırmaya yönelik birtakım yönetim araçlarından yararlanılması beklenmektedir. Nitekim Yang ve Zhuang (2006), milli 
parkların belirli dönemlerinde ziyaretçi sayısının sınırlandırmak için ziyaretçi yönetim araçlarından yararlanılmasının, ziyaretçi deneyim kalitesinin artmasında ve ziyaretçi yoğunluğunun azaltılmasında yardımcı olacağını belirtmiştir. Ziyaretçi yönetim araçlarından biri olan rezervasyon sistemlerinin oluşturulması ziyaretçi yoğunluğunu azaltılmasına ve alanın daha sürdürülebilir kullanımına yardımcı olacaktır.

Milli parklara gelen ziyaretçilerin koruma kullanma konularında bilinçsiz olduğu ve alanı kirlettikleri çıkan ortalamalar neticesinde görülmektedir. Bu anlamda milli park yöneticileri alan ziyaretçi eğitim ve bilgilendirme yönetim aracını benimseyerek, ziyaretçilerin bilgilenmesini sağlayarak koruma -kullanma bilinci oluşturması sürdürülebilir kullanım açısından önemlidir.

\subsection{Milli Parkların Ziyaretçi Yönetim Araçları Açısından İdelenmesi}

Kentlerde açık yeşil alanların azalması, insanların rekreasyonel faaliyetlerini gerçekleştirebilecekleri kente yakın doğal alanlara yönelmektedir. Milli parklar bu doğal alanların başında yer alarak, ziyaretçilerin alan içindeki faaliyetlerinden olumsuz sonuçlara neden olmaktadır. $\mathrm{Bu}$ olumsuz etkiler bütün canlılar üzerinde tehdit oluşturarak, korunan alanların sürdürülebilir kullanımına ters düşmektedir. Dolayısıyla ziyaretçilerin alan üzerindeki olumsuz etkilerini en aza indirgenmesinde ziyaretçi yönetim stratejileri doğrultusunda oluşturulan ziyaretçi yönetim araçlarından yararlanılması beklenilmektedir. Bu doğrultuda milli park yönetim birimleri tarafından, bilgi formunda yer alan 50 adet ziyaretçi yönetim araçlarından hangilerine ihtiyaç olduğu ve uygulanıp uygulanamadıkları sorgulamaların yapmaları istenmiştir. Ziyaretçi yönetim araçları beş ana başlık altında toplanarak veriler elde edilmiştir.

1) Giris ücretlerine yönelik ziyaretci yönetim aracları, milli park ve benzeri alanlarda kullanımların sınırlandırması ve alana maddi kaynak sağlaması yönünden etkili ve önemli ziyaretçi yönetim araçlarından birisidir. Bu uygulama ile ilgili maddelerin değerlendirilmesiyle elde edilen veriler Şekil 3'te verilmiştir. Farklı ücretlendirme politikalarına ilişkin her iki milli parkta uygulanmadıkları görülmektedir. Ancak Küre Dağı milli parkı bu uygulamaların \% 66,7 oranında gerek olduğunu fakat uygulamadıkları görülmektedir.

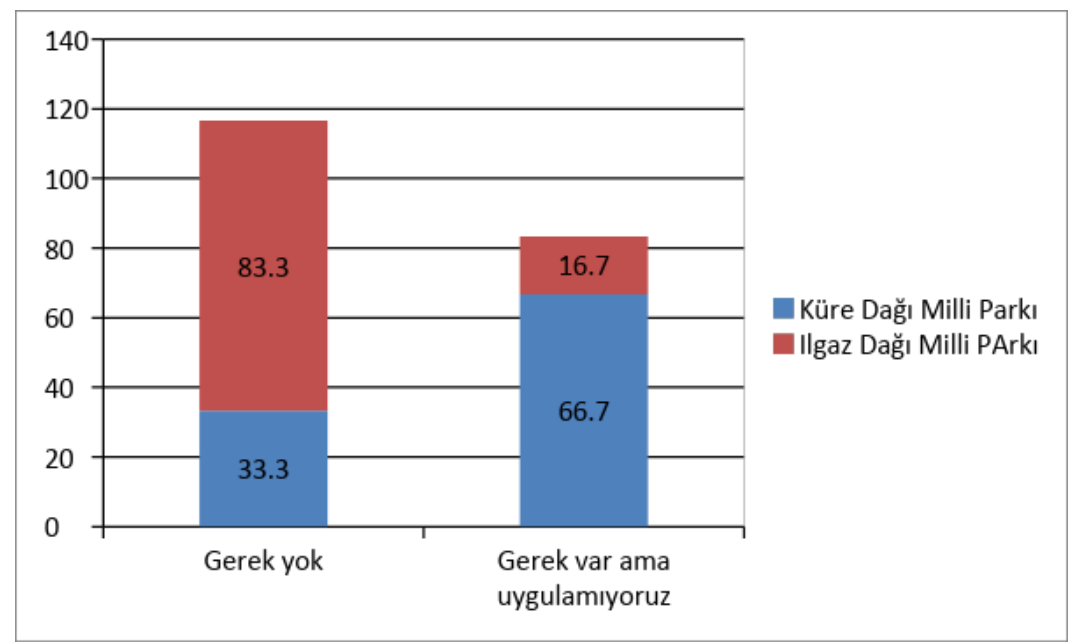

Şekil 3. Farklı ücretlendirme politikaları

Farklı ücretlendirme politikaları, ziyaretçi yoğunluğunun fazla olduğu dönemlerde uygulanması yönünde geliştirilen önemli ziyaretçi yönetim araçlardan birisidir. $\mathrm{Bu}$ uygulama ziyaretçi sayılarını sınırlandırmasının yanı sıra, milli parka daha kaliteli hizmet sunması açısından maddi destek sağlamaktadır. Nitekim Manning ve Lime (2000), korunan alanlara giriş ücretlerinde farklı uygulamalar yapılmasının alan yönetiminde olumlu katkı sağlayacağını belirtmişlerdir.

2) Ziyaretçi ve ekosistemi korumaya yönelik ziyaretçi yönetim aracları, milli park vb. alanlardaki flora, fauna ve toprağın yapısının insan etkilerin korumak amacıyla etkili ve önemli uygulamalardan birisidir. Ayrıca insanları tehlikeli alanlardan uzaklaştırmak amacıyla da bu uygulamadan yararlanılmaktadır. Bu uygulama ile ilgili sorgulamaların sonucunda elde dilen veriler Şekil 4'te sunulmuştur. Bu uygulama Ilgaz Dağı Milli Parkında yarı yarıya $(\% 50)$ oranında uygulandığı görülürken, Küre Dağı Milli Parkı \%25 oranında uygulama yaptıkları görülmektedir. 


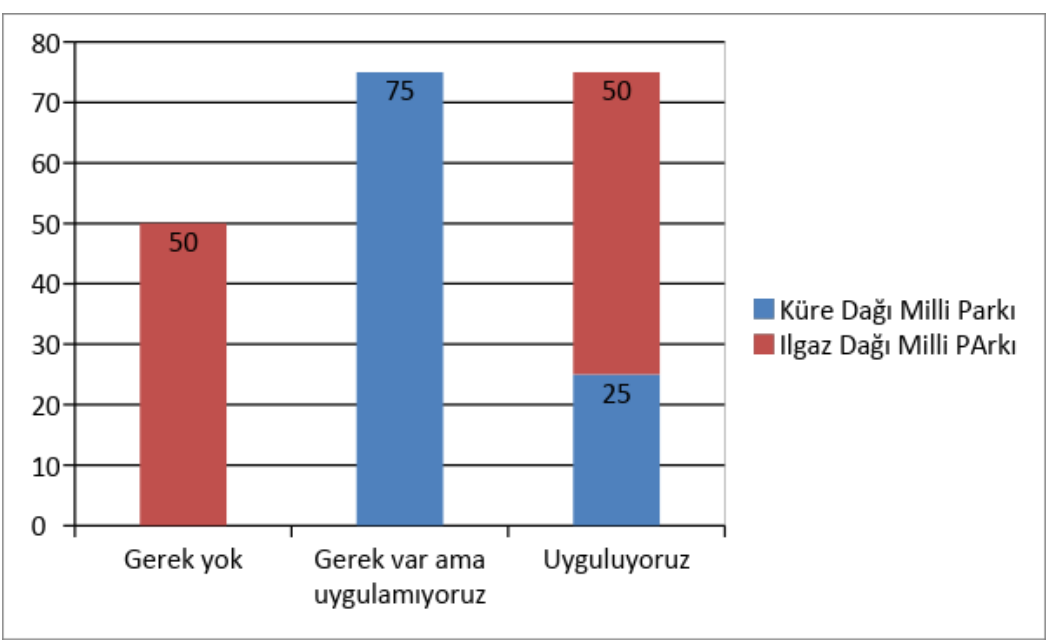

Şekil 4. Bariyer sistemleri

Milli parklara olan talebin giderek artması alan üzerinde olumsuz etkilere neden olmaktadır. Dolaysıyla bu alanların içinde yer alan biyo-çeşitliliğin başta olmak üzere fauna korunması ve toprağın geçirgenliğini sağlanması yönünde bariyer sistemlerinden yararlanılması gerekmektedir. Ayrıca ziyaretçilerin milli parklarda kendilerini güvende hissedecekleri ortamların sağlanması açısından bariyer sistemlerinden oluşturulması ziyaretçilerin memnuniyet düzeyini artmasında yardımcı olacaktır. Bu anlamda her iki milli parkta bariyer sistemlerine olumlu baktıkları görülmektedir.

3)Ziyaretciyi bilgilendirmeye yönelik yapılan ziyaretçi yönetim araçarı, milli parkı ziyaret eden kişilere alan hakkında bilgilendirme yapılması oluşabilecek etkileri azaltmak için önemli bir yönetim aracıdır. Bu uygulama ile ilgili maddelerin değerlendirilmesiyle elde dilen veriler Şekil 5'te gösterilmektedir. Bu yönetim araciyla ilişki verilere bakıldığında her iki milli parkta \% 55’ten fazla oranlarda uygulandığı görülmektedir.

> Milli parklara gelen ziyaretçilere, alan hakkında ve rekreasyonel faaliyetlere başlamadan önce bilgilendirilmelerin yapılması karşılaşılabilecek olumsuzların azaltılmasına yönelik önemli bir ziyaretçi yönetim aracıdır. Dolayısıyla bu alanlarda ziyaretçi farkındalığın artması sürdürülebilirliği sağlanmasında önemli rol oynamaktadır. Ilgaz dağı ve Küre Dağları Milli Parklarında bu yönetim aracına önem verildiği görülmekte olup, kaynak değerlerin koruma kullanma dengesinin sağlanması yönünden önemlidir.

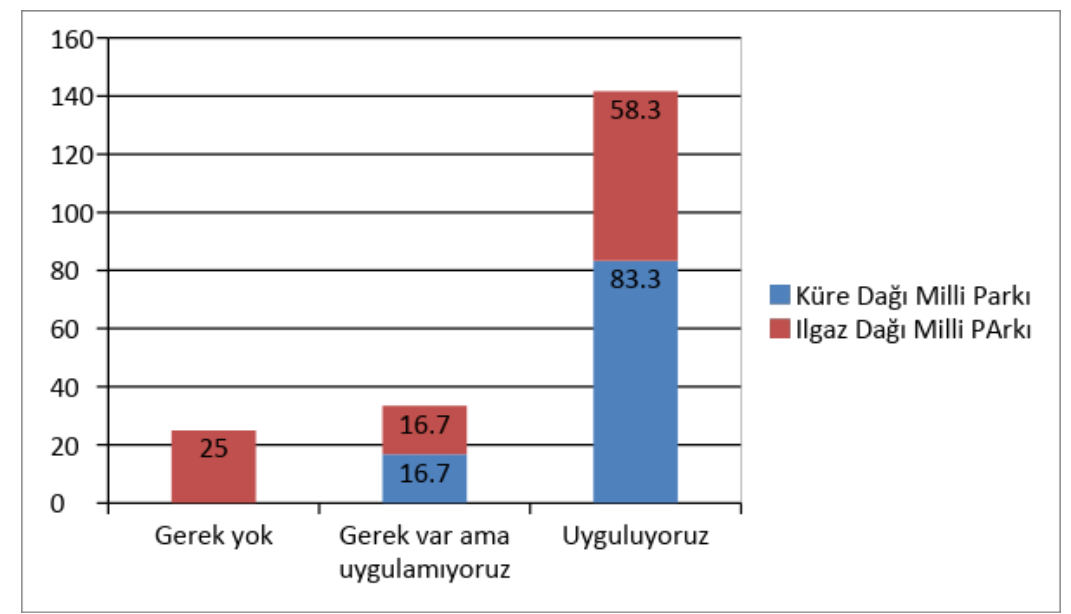

Şekil 5. Ziyaretçi bilgilendirme çalışmaları

4) Taşıma kapasitesine yönelik gelisstirilen zivaretci yönetim aracları, milli parklarda yaşanabilecek ziyaretçi yoğunluğunun önüne geçmek için, ziyaretçilerin alan içerisinde zaman ve mekân açısından eşit dağılımını sağlaması açısından önemlidir. Ankette bu bölümle ilgili sorgular ile ilgili elde edilen veriler Şekil 6'da verilmiştir. Ilgaz Dağı Milli Parkı bu uygulamaların hiç birinin gerek olmadığını belirtirken, Küre Dağı Milli Parkı ise yaklaşık $\% 50$ oranında bu uygulamalardan yararlandıkları görülmektedir. 


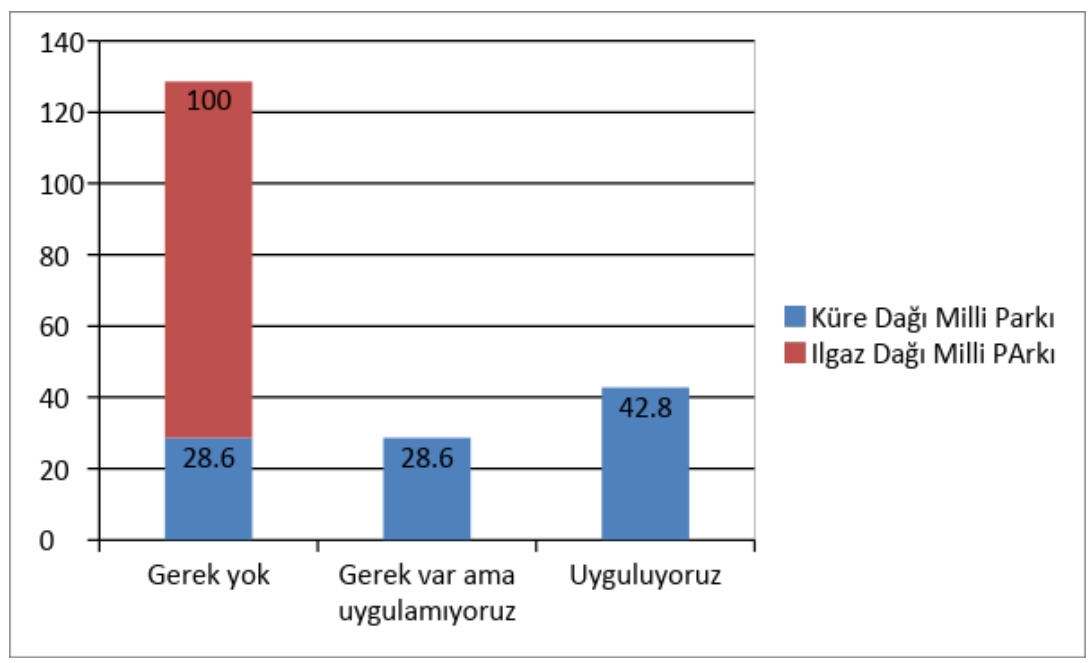

Şekil 6. Taşıma kapasitesine yönelik geliştirilen ziyaretçi yönetim araçları

Mili parklarda yaşanan yoğunluklarda ziyaretçi memnuniyetsizliğinde düşüşlere ve hassas ekosistemlere sahip alanlardaki rekreasyonel aktiviteler bitki örtüsünün azalmasına neden olacaktır. Bu yüzden bu etkilerin azaltılmasında alanın kaldırabileceği kişi sayısı doğrultusunda sınırlandırmalar yapılması önemli bir yaklaşımdır. Bu uygulamalar ile alana kaynak değer bakımından değer sağlayan zenginliklerin sürdürülebilir bir şekilde kullanılmasını sağlayacaktır. Bu bakımdan Küre Dağları Milli Parkı bu uygulamalara daha önem verdiği görülmektedir.

5) Alanın etkin kullanımına yönelik geliștirilen ziyaretçi yönetim araçları, milli parkların sahip olduğu kaynak değerlerin süründürülebilir kullanıldığı sürece kendisinden beklenen hizmet ve faydaları gösterebilir. Dolayısıyla koruma-kullanma dengesi göz önünde bulunduracak şekilde, alanın etkin kullanılmasına yönelik geliştirilen ziyaretçi yönetim araçlarının uygulanması olumlu sonuçların ortaya çıkmasına yardımcı olacaktır. Bu konuyla ilgili alanların değerlendirilmesiyle elde edilen veriler Şekil 7'de gösterilmektedir. Ilgaz Dağı Milli Parkı bu uygulamaların \% 77,3 oranında gerek olmadığı belirtirken, Küre Dağı Milli Parkı ise \% 50 oranında gerek olduğu fakat uygulamadıklarını belirtmiştir.

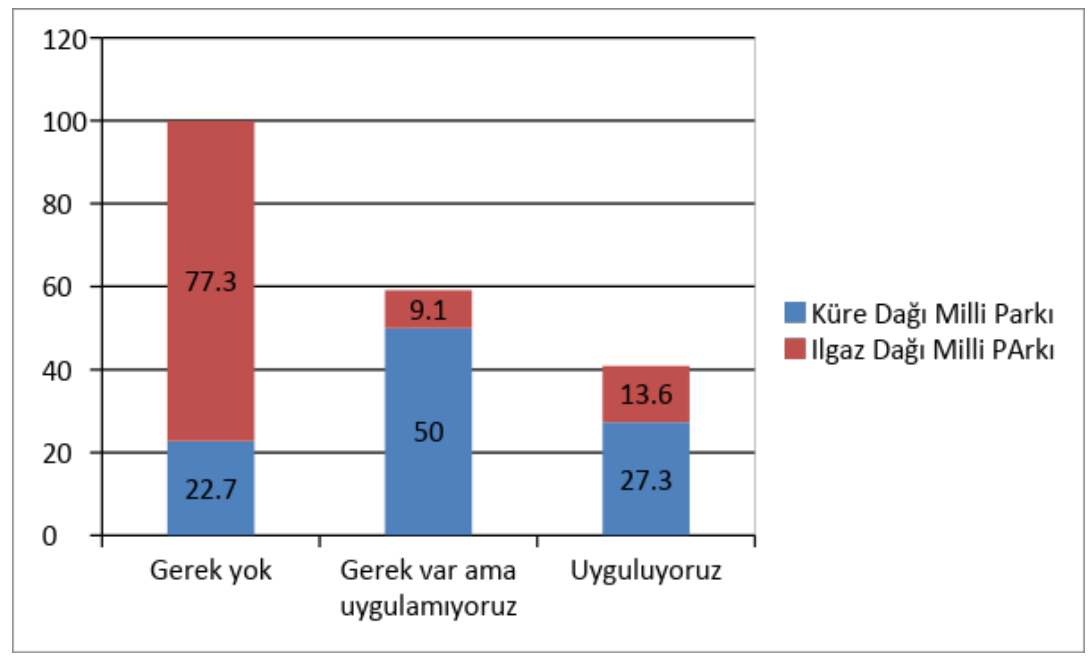

Şekil 7. Alanın etkin kullanımına yönelik geliştirilen ziyaretçi yönetim araçları

Yıldırım ve Erol (2012)'a göre, milli park gibi korunan alanlardan beklenilen faydaların yararlanılabilmesi için bu alanların katılımcı ve sürdürülebilir bir yaklaşımla yönetilmesini gerektiğini belirtmişlerdir. Dolayısıyla alanın koruma-kullanma dengesini gözeterek oluşturulan ziyaretçi yönetim araçlarından yararlanılması önemlidir. Küre Dağları Milli Parkı bu uyguları dikkate alması, kaynak değerlerin sürdürülebilirliğin sağlanmasında önemli gelişmelerdir. 
Ziyaretçilerin milli park gibi koruma statüsüne sahip alanlardaki doğal ve kültürel kaynak değerleri üzerindeki etkilerini azaltmak, sürdürülebilirlik çerçevesinde kullanımları sağlamak için ziyaretçi yönetim araçlarına önem verilmelidir. Bu anlamda Ilgaz Dağı ve Küre Dağları Milli Parklarının ziyaretçi yönetim araçlarına olan eğilimin toplam yüzdeleri Şekil 8'de verilmiştir. Buna göre, Küre Dağları Milli Parkı'nın (\% 40,4) Ilgaz Dağı Milli Parkı'ndan (\% 26,9) daha fazla uygulandığı görülmektedir.

Korunan alanlar içerinde önemli bir alanı kapsayan milli parklar, doğal ve kültürel kaynak değerlerin korunması için etkili yönetim planlarının hazırlanması gerekmektedir. Bu yüzden ziyaretçi yönetim planlarını hazırlanırken koruma kullanmaya yönelik geliştirilen ziyaretçi yönetim araçları uygulanmalı ve denetimin sağlanması sürdürülebilir kullanım açısından önemli rol oynamaktadır.

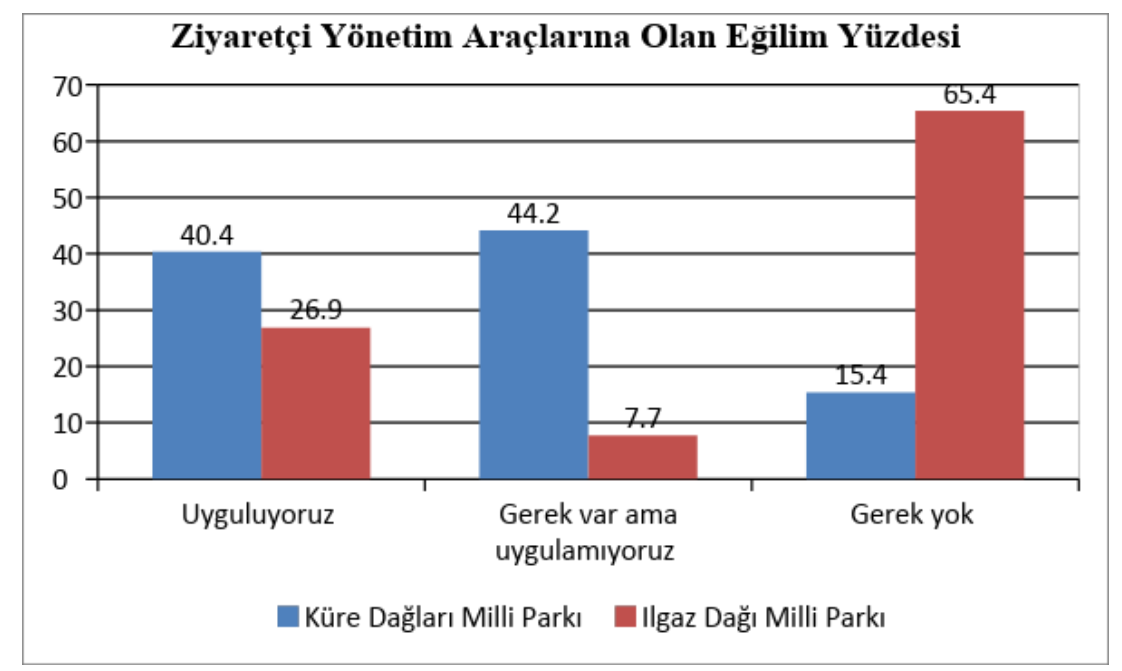

Şekil 8. Ziyaretçi Yönetim Araçlarına Olan Eğilimin Yüzdesi

\section{Sonuç ve Öneriler}

Milli parklar, sağladığı rekreasyon olanaklar ile ekonomik olarak faydaya dönüştürürken, artan ziyaretçi sayısı ile birlikte alanın kaynak değerleri üzerinde olumsuz etkilere yol açmaktadır. Dolayısıyla milli parklarda koruma kullanma dengesi sağlanarak, alan içinde oluşabilecek ziyaretçilerin memnuniyet düzeylerindeki düşüşlerin önüne geçilmelidir. Bu bağlamda milli parkların sahip olduğu doğal, kültürel ve rekreasyonel kaynak değerlerin korunması, geliştirilmesi ve devamlılığını sağlayacak taşıma kapasitesi tabanlı ziyaretçi yönetim planlarının oluşturulması sürdürülebilirlik anlayışı için önemlidir.

Milli parklarda kullanım yoğunluğunun ve rekreasyon etkinliklerinin artması nedeniyle, bu alanlarda gerçekleştirilen kullanımların optimum sınırları ve kullanım yoğunluklarının belirlenmesi ve uygun kullanım tiplerinin saptanmasına yönelik etkili yönetim stratejileri geliştirilmelidir. Ziyaretçi yönetim stratejilerinin etkin bir şekilde uygulanabilmesi için ziyaretçi yönetim araçlarından yararlanılmaktadır. Ziyaretçi yönetim araçları, alanda oluşabilecek olumsuzluklara karşı önlem alınması yönünde geliştirilen sınırlandırmalar, etkinlikler veya çözümler olarak tanımlanabilir. Bu yüzden çalışmada, Küre Dağları ve Ilgaz Dağı Milli Parklarında ziyaretçi etkilerini azaltmaya yönelik yararlanılan ziyaretçi yönetim araçları incelenmiş ve sürdürülebilirlik çerçevesinde iki başlık altında öneriler getirilmiştir.

Küre Dağı ve Ilgaz Dağları Milli parklarında karşılaşılan yönetimsel sorunlara yönelik;

- Her iki mili parkta yaşanan yönetim sorunlarından en önemlisi, mevcut personelin az olduğu görülmektedir. Bu yüzden korunan alanların yönetimi hususundaki, nitelikli personel sayısını arttırılmalı, personellerin hizmet içi kalitesini arttırılmasında eğitim çalışmalarına önem verilmeli ve personelin yurt dışındaki önemli milli parklara götürülerek, uygulanan ziyaretçi yönetim planları konusunda bilgi edinmesi sağlanmalıdır. Böylece güçlü bir yönetim biriminin olması, alanın süründürülebilir kullanılmasında önemli rol oynayacaktır.

- Etkili yönetim planlarında öncelikli olarak alanın taşıma kapasitesi analizleri yapılması, ziyaretçi yoğunluğunu azalmasına ve doğa üzerindeki olumsuz etkileri ortadan kaldırmasına yardımcı olur. Ilgaz Dağı Milli Parkının taşıma kapasiteleri yapılmasına rağmen, taşıma kapasitesini azaltıcı uygulamalardan 
kaçındığı görülmektedir. Bu yüzden bu analizleri göz önünde bulundurulması, kaynak değerlerin sürdürülebilir kullanımına yardımcı olacaktır.

Küre Dağı ve Ilgaz Dağları Milli parklarında uygulanan ziyaretçi yönetim araçlarına yönelik;

- Milli parklar sağladığı rekreasyonel faaliyetler, ziyaretçilerin bu alanlara eğilimini artırarak, ziyaretçi yoğunlukları oluşmaktadır. Dolayısıyla oluşan bu yoğunluklar hem alanı olumsuz etkilemekte hem de ziyaretçi memnuniyet seviyesini düşürmektedir. Bu bağlamda ziyaretçi yoğunluğunu azaltmaya yardımcı yönetim araçlarından birisi farklı ücretlendirme politikalardır. Bu yönetim aracı sayesinde hem alan kullanımını sınırlandırma hem de alan yönetimine maddi kaynak sağlaması açısından önemli olup, milli parklar tarafindan benimsenmesi gereken bir uygulamadır. Her iki milli parka baktı̆̆ımızda bu uygulamalardan yararlanmadığı görülse de, Küre Dağı Milli Parkının farklı ücretlendirme politikalarına gerek olduğunu farkında olması, sürdürülebilirlik açısından önemli bir aşamadır.

- Milli parkların zengin bitki çeşitliliğinin ziyaretçi etkilerinden ve aynı zamanda ziyaretçileri alan içindeki tehlikeli bölgelerden korumak için geliştirilen ziyaretçi yönetim araçlarından biri olan bariyer sistemi, ziyaretçi yönetim planlamalarında olması gereken önemli bir yaklaşımdır. Dolayısıyla bu ziyaretçi yönetim aracı hem milli parkların kaynak değerlerin korunmasına yardımcı olurken hem de ziyaretçi deneyim kalitesini artırmaktadır. Küre Dağları Milli Parkında bu uygulamalardan yüzde oranında daha az yararlanmasına rağmen, uygulamadıkları yönetim araçların da gerekli olduğunu belirtmiştir. $\mathrm{Bu}$ da sürdürülebilirlik kapsamında önemli gelişmelerdendir.

- Ziyaretçilerin milli park gibi koruma statüsüne sahip alanlardaki doğal ve kültürel kaynak değerleri üzerindeki etkilerini azaltmak, sürdürülebilirlik çerçevesinde kullanımları sağlamak için yararlanılan önemli ziyaretçi yönetim araçlarından birisi ziyaretçi eğitim ve bilgilendirme uygulamalardır. Bu ziyaretçi yönetim aracı ziyaretçilerin doğal ve kültürel kaynak değerlerinin korunmasını ve temiz çevre oluşturma anlayışını geliştirerek, daha etkili bir yönetim sağlayacaktır. Bu anlamda, Küre Dağı ve Ilgaz Dağı Milli Parklarda bu uygulamalardan yararlanması, sürdürülebilirlik açısından önemli adımlardandır.

Sonuç olarak, çalışma kaynak değerleri bakımından zengin olan milli parkların koruma kullanma dengesinin sağlanmasında önemli yarar sağlamaktadır. Gelişmiş ülkelerde yer alan pek çok milli parkta etkin ziyaretçi yönetimi için ziyaretçi yönetim araçlarına dikkate alan planlamalar hazırlamaktadır. Bu anlamda ülkemizdeki milli parklarda da bu tür uygulamaların artması sürdürülebilir ilkesinin tam anlamıyla ortaya çıkmasını sağlayacaktır.

\section{Teşekkür}

Bu çalışma, 2018 Uluslararası Ekoloji Sempozyumunda sözlü bildiri olarak sunulup, bildiri kitapçığında özet olarak basılmıştır.

\section{Kaynaklar}

1. Akten, S., Gül, A. (2014). Korunan doğal alanlarda ziyaretçilerin olası etki düzeyleri önlem ve standartların belirlenmesi (Gölcük Tabiat Park1 örneği). Türkiye Ormancllık Dergisi, 15(2), 130-139.

2. Anonim (2019a). Küre Dağları Milli Parkı. https://www.kdmp.gov.tr/kdmp-hakkinda/kure-daglarimilliparki.

3. Anonim (2019b). Ilgaz Dağı Milli Parkı. http://ilgazdagi.tabiat.gov.tr/.

4. Anderson, D.H., Lime, D.W., Wang, T.L. (1998). Maintaining the Quality of Park Resources and Visitor Experiences. A Handbook For Managers, University Of Minnesota.

5. Anonymous (2002). "Public Participation in Protected Area Management Best Practice" Prepared for: The Committee on National Parks and Protected Area Management, Benchmarking and Best Practices Program, Prepared By; Parks and Wildlife Commission of the Northern Territory, Avustralya ve Yeni Zellanda.

6. Buckley, R. (2003). Pay to play in parks: An Australian policy perspective on visitor fees in public protected areas. Journal of Sustainable Tourism, 11(1), 56-73.

7. Cullinane, S., Cullinane, K. (1999). Attitudes towards traffic problems and public transport in the Dartmoor and Lake District National Parks. Journal of Transport Geography, 7(1), 79-87.

8. Çoban, G. (2016). Milli Parklarda Koruma-kullanma Dengesinin Sağlanması Yönünde Geliştirilen Ziyaretçi Yönetim Araçlarının İncelenmesi, Aydın Adnan Menderes Üniversitesi Fen Bilimleri Enstitüsü, Peyzaj Mimarlığı Anabilim Dalı, Aydın.

9. Eagles, P.F., McCool, S.F., Haynes, C.D. (2002). Sustainable tourism in protected areas: Guidelines for planning and management. Gland: IUCN, Vol. 8.

10. Eaton, B., Holding, D. (1996). The evaluation of public transport alternatives to the car in British National Parks. Journal of Transport Geography, 4(1), 55-65. 
11. Ersoy, İ., Daşdemir, İ. (2016). Korunan Alanlarda Yönetimin Etkinlik Düzeyinin Belirlenmesi (Soğuksu Ve Yozgat Çamlığı Milli Parkları Örneği). Journal Of Bartın Faculty Of Forestry, 18(1), 32-46.

12. Farrell, T.A., Marion, J.L. (2000). Camping impact management at Isle Royale National Park: an evaluation of visitor activity containment policies from the perspective of social conditions.

13. Göktuğ, T.H., Arpa, N.Y. (2015). Korunan Alanlar Yönetimi Bağlamında Kayak Merkezilerinin Fiziksel ve Sosyal Taşıma Kapasitelerinin Analizi: Ilgaz Dağı Milli Parkı, Ilgaz Kış Sporları Turizm Merkezi. Kastamonu Üniversitesi Orman Fakültesi Dergisi, 15(1).

14. Göktuğ, T.H., Kurkut, G. (2016). 'Korunan Alanlarda Sürdürülebilir Ziyaretçi Yönetimi: Stratejiler Ve Araçların İncelenmesi.' Journal Of Bartın Faculty Of Forestry, 18(1), 118-131.

15. Greist, D. (1975). Risk zone management: A recreation area management system and method of measuring carrying capacity. Journal of Forestry. 73, 711-714.

16. Haas, G., Driver, B., Brown, P., Lucas, R. (1987). Wilderness Management Zoning. Journal of Forestry. $85,17-22$.

17. Heywood, J. (1985). Large recreation group and party size limits. Journal of Park and Recreation Administration, 3, 36-44.

18. Kervankıran, İ., Eryılmaz, A.G. (2015). Milli Parkların Sürdürülebilir Kullanımı ve Yönetim Planı Önerisi: Isparta İli Örneği. Süleyman Demirel Üniversitesi Sosyal Bilimler Dergisi, 34, 173-190.

19. Lindberg, K., Halpenny, E. (2001). Protected area visitor fees: overview.Generating revenue through ecotourism for marine protected areas in Belize. A report of the Summit Foundation, International Ecotourism Society and Programme for Belize.

20. Manning, R. (1999). Crowding and Carrying Capacity in Outdoor Recreation: From Normative Standards to Standards of Quality. In E. Jackson and T. Burton (eds.), Leisure Studies: Prospects for the Twenty First Century. State College, PA: Venture Publishing, 323-34.

21. Manning, R.E., Lime, D.W. (2000). Defining and managing the quality of wilderness recreation experiences.

22. Manning, R. (2003). Emerging principles for using information/education in wilderness management. International Journal of Wilderness, 9(1), 20-27.

23. Marion, J.L., Reid, S.E. (2007). Minimising visitor impacts to protected areas: The efficacy of low impact education programmes. Journal of Sustainable Tourism, 15(1), 5-27.

24. Mason, P. (2005). Tourism and hospitality. Planning \& Development 2 (3), 171-190.

25. Park, L.O., Manning, R.E., Marion, J.L., Lawson, S.R., Jacobi, C. (2008). Managing visitor impacts in parks: A multi-method study of the effectiveness of alternative management practices. Journal of Park and Recreation Administration, 26(1), 97-121.

26. Masters, D., Scott, P., Barrow, G. (2002). Sustainable Visitor Management System: A Discussion Paper. In Unpublished Paper. Participatory Workshop, Battleby Centre, Perth.

27. Öztürk, S. (2005). Kastamonu-Bartın Küre Dağları Milli Parkı'nın Rekreasyonel Kaynak Değerlerinin İrdelenmesi. Turkish Journal Of Forestry, 2, 138-148.

28. Roggenbuck, J., Schreyer, R. (1977). Relations between river trip motives and perception of crowding, management preference, and experience satisfaction. Proceedings: River Recreation Management and Research Symposium. USDA Forest Service General Technical Report, NC-28: 359-364.

29. Singer, F.J., Beattie, J.B. (1986). The controlled traffic system and associated wildlife responses in Denali National Park. Arctic, 195-203.

30. Şen, G., Buğday, S.E. (2015). Kastamonu İlinde Çeşitli Statülerde Koruma Ve Kullanma Amaçlı Belirlenmiş Alanlar. Kastamonu Üniversitesi Orman Fakültesi Dergisi, 15(2), 214-230.

31. Yang, R., Zhuang, YOUBO (2006). Problems and solutions to visitor congestion at Yellow Mountain National Park. China. Int. J. Prot. Area Manage, 16(2), 47-52.

32. Yıldırım, H.T., Erol, S.Y. (2012). Korunan Alanlar, Ekolojik İşlevleri Ve Geleceğe Yönelik Tahminler. Biyoloji Bilimleri Araştırma Dergisi, (2), 101-109. 